\title{
BOM PARA VENDER, BOM PARA COMER, BOM PARA SE VER: um olhar por entre as coisas de comer nas ruas e esquinas da Grande Belém
}

Miguel Brito Picanço ${ }^{1}$

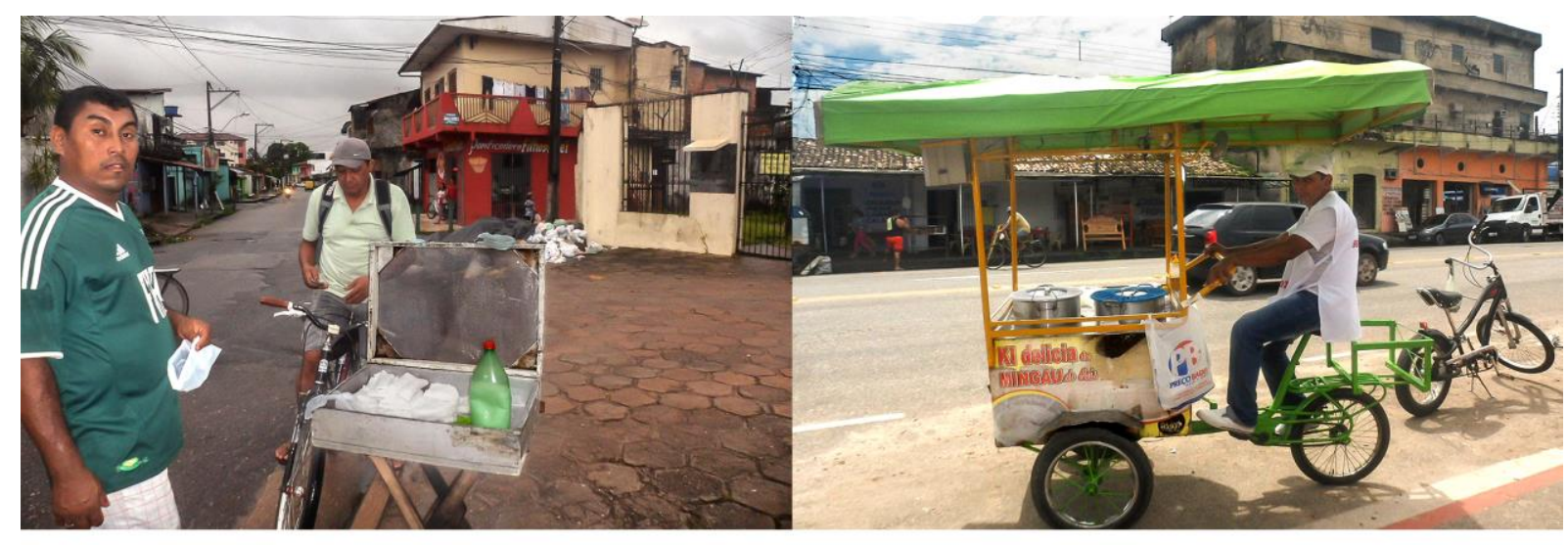

1.

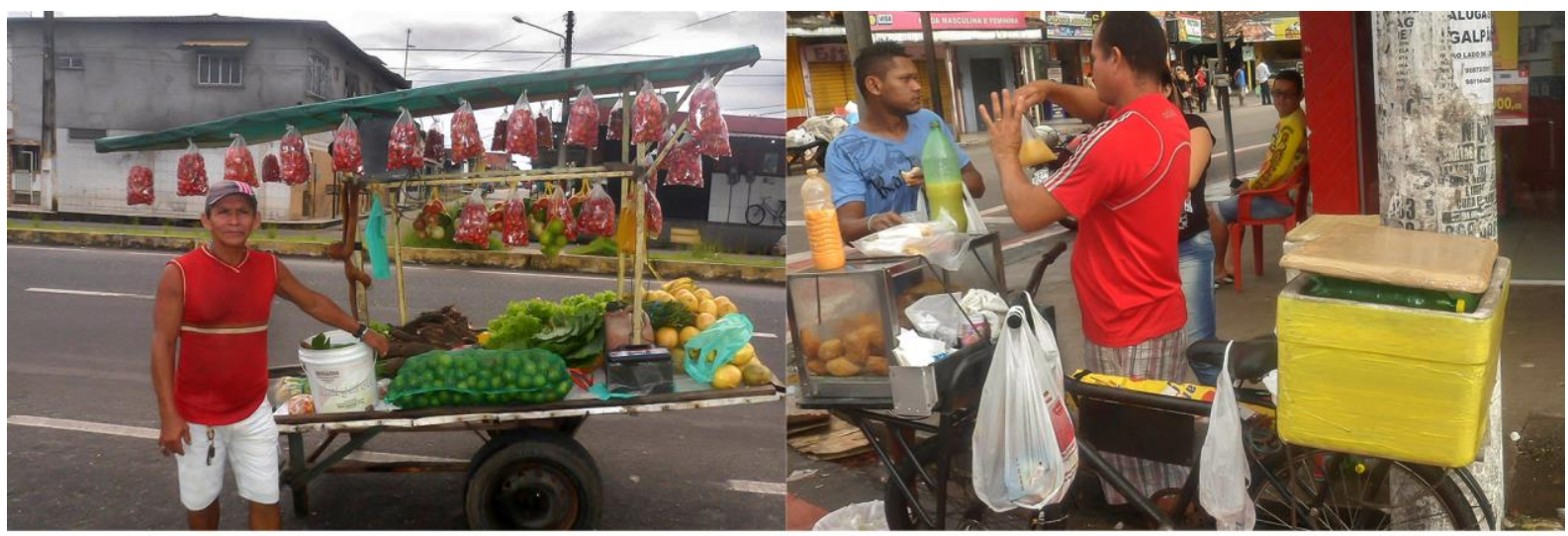

3.

\footnotetext{
${ }^{1}$ Doutorando Pelo Programa de Pós-Graduação em Ciências Sociais da Universidade do Vale do Rio dos Sinos na linha de pesquisa: identidade e sociabilidade, na modalidade Doutorado Sanduíche (Bolsa/CAPES), com estágio doutoral pela Universidad de Barcelona no Observatorio de la Alimentación. Compõe a equipe de pesquisadores do Laboratório de Políticas Culturais e Ambientais do Brasil (LAPCAB). É Mestre em Ciências da Educação e graduado em Ciências Sociais, com ênfase em Antropologia da Cultura. E-mail: micanbri2013@gmail.com.
} 


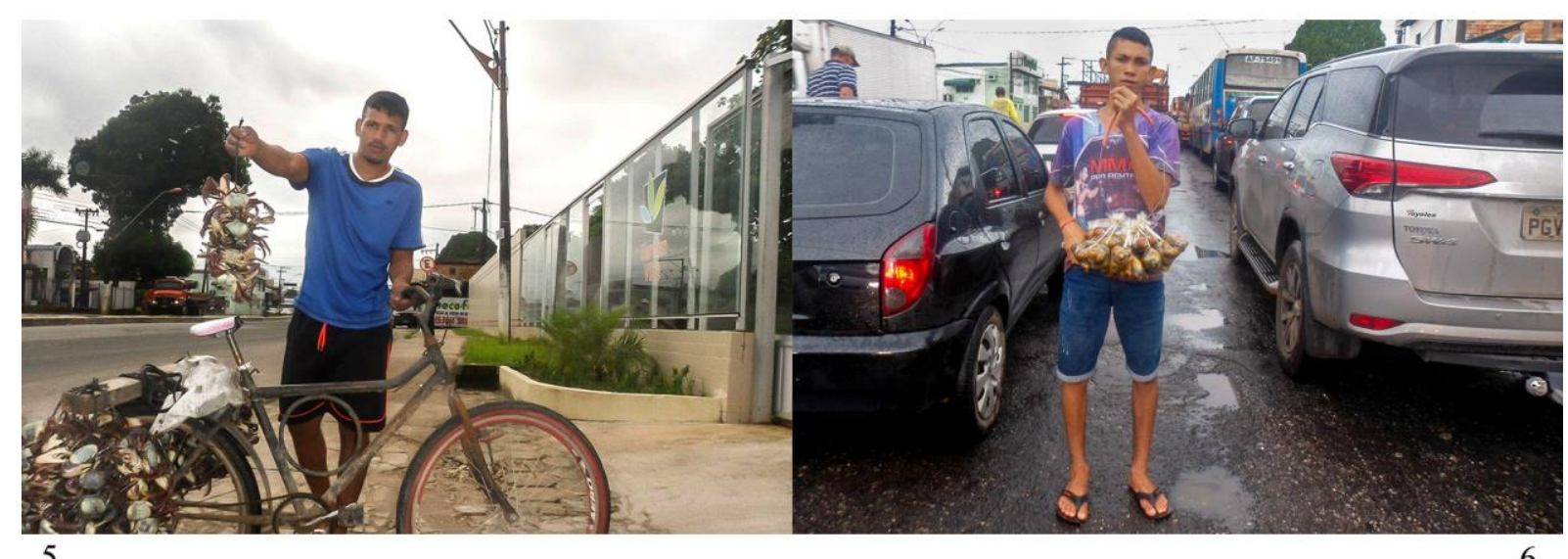

5.

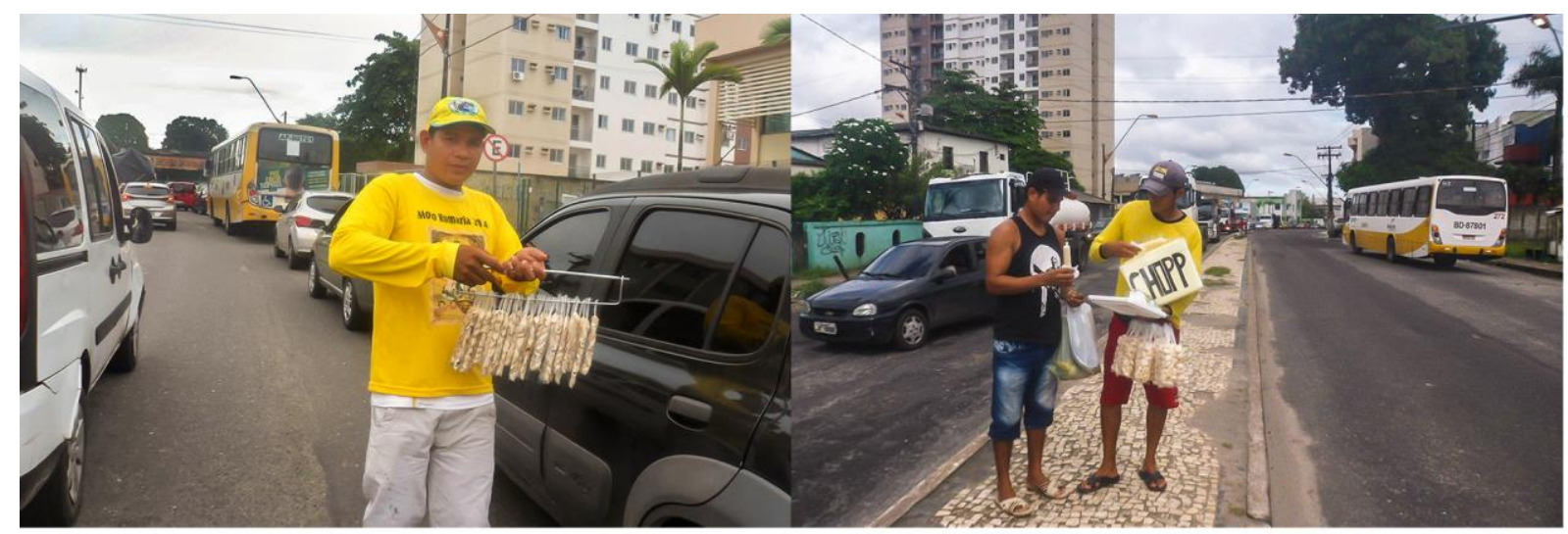

7.

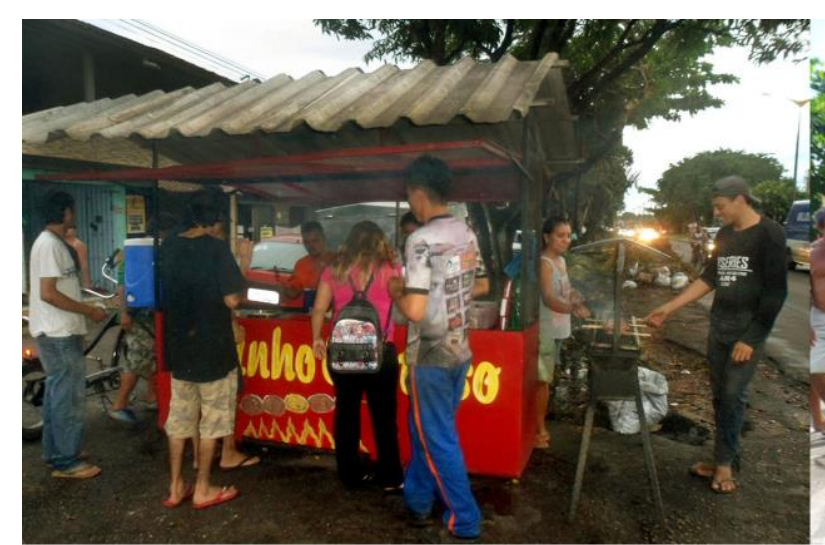

9. 
Pato no tucupi, maniçoba e tacacá são alguns elementos da culinária paraense que, no decorrer do tempo, têm marcado e definido as identidades coletivas do povo belenense e aguçado o interesse da comunidade acadêmica em tê-los com objeto de estudo e pesquisa. Por outro lado, existem outros elementos, coisas, pessoas e práticas que também compõem e marcam essas identidades, povoando o cotidiano das ruas e esquinas das periferias da Grande Belém, e quiçá de bairros centrais da cidade, mas que de certa maneira parecem alheios aos interesses supracitados.

Estou falando dos "caranguejeiros", "tapioqueiros", "migauzeiros", “completeiros", "chopeiros", "pupunheiros", "verdureiros", dentre outros. Suas respectivas comidas historicamente resistem ao tempo e à modernidade, sendo consumidas cotidianamente por entre as ruas da capital paraense, onde desempenham papel fundamental na dinâmica da cidade, contribuindo para sua sustentabilidade econômica e, ao mesmo tempo, potencializando a permanência de sua identidade coletiva. São, portanto, desses elementos, coisas, pessoas e práticas que falam as imagens deste ensaio.

Essas práticas são regidas por tratativas, onde os sujeitos que as protagonizam são respectivamente fregueses e não clientes. E é exatamente nessa condição de ser freguês que reside a capacidade do fenômeno de se configurar em relações de consumo que não se findam em negociações meramente mercantis. Ao contrário, são práticas eminentemente culturais que desempenham papel decisivo na construção e estreitamento de laços sociais, assim como no enfrentamento de mudanças, ou na criação de permanências, por entre os interstícios da modernidade e dos contextos urbanos.

Sendo assim, considerando as prerrogativas de Douglas; Isherword (2006), Rocha (2006), Appaduari (2008) e Contreras; Gracia (2011), as tratativas em torno dessas experiências de consumo mencionadas não podem ser compreendidas apenas como um fenômeno inerente ao mercado global; são, antes disso, práticas eminentemente culturais que dizem respeito à satisfação do desejo de comer algumas coisas que foram elaboradas no bojo das construções das identidades coletivas daqueles que as consomem pelas ruas e esquinas de Belém. 
Nessa perspectiva, argumenta-se aqui que essas experiências ainda permanecem em meio aos processos globais, que tendem a homogeneizar todos os campos da vida, inclusive aqueles referentes à alimentação, porque a comida é dotada de representações simbólicas e emocionais ativadas pela satisfação de poder degustar um alimento que outrora povoou aqueles hábitos alimentares, de acordo com gostos e preferências específicas (CONTRERAS; GRACIA, 2011).

Assim, acredita-se que o consumo das comidas vendidas nesses espaços urbanos emerge como linguagem e imagem de identidade. Como sinônimo do que pode reforçar e tornar coeso o povo paraense, como fenômeno "[...] eminentemente social, relacional e ativo, em vez de privado, atônico ou passivo [...]” (APPADURAI, 2008, p. 48). Um fenômeno, a priori, da ordem cultural e, a posteriori, de cunho mercadológico (DOUGLAS; ISHERWOOD, 2006), que desempenha papel central na construção e permanência das identidades coletivas, "na regulação das relações sociais, assim como na definição [...] de mapas culturais [...] e, como tal, é investido [...] de valores socialmente utilizados para expressar categorias e princípios, cultivar ideias, fixar e sustentar estilos de vida, enfrentar mudanças ou criar permanências" (ROCHA, 2006, p. 8).

Desde o ano de 2015, este paraense e aprendiz de antropólogo tem se empenhado em estudar algumas experiências de consumo e comensalidades no contexto urbano de Belém, direcionando o olhar para aquelas práticas "banais", corriqueiras, cujo lócus de estudo e pesquisa reside especialmente nas periferias desta cidade e sua região metropolitana. $\mathrm{O}$ objetivo do estudo é descobrir as razões que fazem com que essas experiências, relativamente antigas, mantenham-se, apesar do contínuo processo de modernização da cidade.

Portanto, os dados dessa investigação estão sendo coletados a partir de observação em campo, conversas e entrevistas. Juntamente com esses recursos metodológicos, optou-se também pelo uso da fotografia como instrumento de coleta de dados. A escolha por esse recurso se deu com o intuito de captar aqueles detalhes, aquelas especificidades da realidade estudada que, às vezes, escapam a outras técnicas de pesquisa, pois a fotografia permite captar detalhes empíricos que normalmente não se mostram à primeira vista (SAMAIN apud ACHUTTI, 2004: 83). São detalhes que se escondem por detrás da aparência, não foram ditos ou escritos e que, às vezes, só a fotografia pode revelar. 


\section{Fotografias / Legendas:}

1 - TAPIOQUEIRO: vendedor de tapioca, uma espécie de beiju, feita da goma de mandioca. É historicamente servida na mesa dos belemenses, em especial, no café da tarde.

2 - MINGAUZEIRO: vendedor de mingau, que pode ser de milho branco ou de tapioca. Os mingauzeiros são encontrados nas periferias de Belém, especialmente, nos fins de tarde.

3 - VERDUREIRO: vendedor de verduras, frutas e legumes. Os verdureiros circulam, pelas manhãs, nas ruas de Belém.

4 - COMPLETEIRO: vendedor de lanche, chamado de completo em Belém. Corresponde a um saquinho de suco de sabor variado, acompanhado de um doce ou um salgado (coxinha, pastel etc).

5 - CARANGUEJEIRO: vendedor de caranguejo, crustáceo muito apreciado pelos paraenses principalmente nos fins de semana. Nesses dias, os caranguejeiros se espalham pelas ruas e esquinas de Belém, notadamente nas periferias da cidade.

6 - PUPUNHEIRO: vendedor de pupunhas, frutas tipicamente amazônicas que acompanham o café dos paraenses. Os pupunheiros são facilmente encontrados nos fins de tarde pelas ruas de Belém, especialmente nos semáforos da cidade.

7 - CASTANHEIRO: vendedor de castanhas do Pará. Os castanheiros são encontrados com regularidade nas ruas de Belém, especialmente, nos semáforos da cidade.

8 - CHOPEIRO: vendedor de chop, comida tipicamente paraense feita de sucos de frutas regionais armazenados em pequenos sacos e que, depois de congelados, são vendidos principalmente nos semáforos de Belém.

9 - CHURRASQUEIRO: vendedor de churrasquinho de gato, que consiste em pedaços pequenos de carne bovina, frango e calabresa, espetados em um graveto. Depois de assado, é comido acompanhado de farinha d'água e pimenta. Os churrasqueiros são encontrados exclusivamente nos fins das tardes pelas esquinas das periferias de Belém.

10 - TUCUPIZEIRO: vendedor de tucupi, um suco amarelado retirado da mandioca e utilizado como o principal ingrediente para feitura do pato no tucupi - o prato central do almoço do Círio de Nazaré. Os tucupizeiros são regularmente encontrados nas feiras de Belém, porém, no tempo do Círio, eles se espalham pelas ruas da cidade, porque nessa época há um considerável aumento na demanda do produto. 


\section{Referências bibliográficas}

ACHUTTI, Luiz Eduardo Robinson. Fotoetnografia da Biblioteca Jardim. Porto Alegre: Editora da UFRGS, 2004.

APPADURAI, Arjun. "Introdução: mercadorias e a política de valor". In: APPADURAI, Arjun (Org). A vida social das coisas: as mercadorias sob uma perspectiva cultural. $1^{\mathrm{a}} \mathrm{Ed}$. Niterói: Universidade Federal Fluminense, 2008.

CONTRERAS, Jesús; GRACIA, Mabel. Alimentação, sociedade e cultura. Rio de janeiro: Fiocruz, 2011.

DOUGLAS, Mary; ISHERWOOD, Baron. O mundo dos bens: para uma antropologia do consumo. $1^{\text {a }}$ Ed. Rio de Janeiro: UFRJ, 2006.

ROCHA, Everardo. "Os bens como cultura: Mary Douglas e a antropologia do consumo". In: DOUGLAS, Mary; ISHERWOOD, Baron (Orgs). O mundo dos bens: para uma antropologia do consumo. $1^{\text {a }}$ Ed. Rio de Janeiro: UFRJ, 2006.

Recebido em: 26/07/2017

Aceito em:11/12/2017 